\title{
Existence and higher arity iteration for total asymptotically nonexpansive mappings in uniformly convex hyperbolic spaces
}

\author{
Muhammad Aqeel Ahmad Khan ${ }^{1 *}$, Hafiz Fukhar-ud-din ${ }^{2,3}$ and Amna Kalsoom ${ }^{3}$
}

\section{"Correspondence:}

itsakb@hotmail.com

'Department of Mathematics,

COMSATS Institute of Information

Technology, Lahore, 54000, Pakistan

Full list of author information is

available at the end of the article

\begin{abstract}
This paper provides a fixed point theorem and iterative construction of a common fixed point for a general class of nonlinear mappings in the setup of uniformly convex hyperbolic spaces. We translate a multi-step iteration, essentially due to Chidume and Ofoedu (J. Math. Anal. Appl. 333:128-141, 2007) in such a setting for the approximation of common fixed points of a finite family of total asymptotically nonexpansive mappings. As a consequence, we establish strong and $\triangle$-convergence results which extend and generalize various corresponding results established in the current literature.
\end{abstract}

MSC: Primary 47H09; 47H10; secondary 49M05

Keywords: total asymptotically nonexpansive mapping; common fixed point; hyperbolic space; modulus of uniform convexity; asymptotic center

\section{Introduction}

Let $(X, d)$ be a metric space and $x, y \in X$ with $l=d(x, y)$. A geodesic from $x$ to $y$ in $X$ is a mapping $\theta:[0, l] \rightarrow X$ such that

$$
\theta(0)=x, \theta(l)=y \quad \text { and } \quad d(\theta(s), \theta(t))=|s-t| \quad \text { for all } s, t \in[0, l] .
$$

The above characteristics is referred to as a constant speed of $\theta$, the parametrization of $\theta$ with respect to the arc length or distance preservation of $\theta$. The points $x=\theta(0)$ and $y=\theta(l)$ are called the end points or the extreme (maximal or minimal) points of the segment. The metric space $(X, d)$ is called a geodesic space if for every pair of points $x, y \in X$, there is a geodesic segment from $x$ to $y$. Moreover, $(X, d)$ is uniquely geodesic if for all $x, y \in X$ there is exactly one geodesic from $x$ to $y$.

The class of hyperbolic spaces introduced by Kohlenbach [2] is an important example of a uniquely geodesic space. It is worth to mention that this class is prominent among various other notions of hyperbolic spaces in the current literature, for convenience of the reader; see [3-6]. The study of hyperbolic spaces has been largely motivated and dominated by questions about hyperbolic groups, one of the main objects of study in geometric group theory. We remark that the non-positively curved spaces, such as hyperbolic spaces, play a significant role in many branches of applied mathematics.

(c) 2016 Khan et al. This article is distributed under the terms of the Creative Commons Attribution 4.0 International License (http://creativecommons.org/licenses/by/4.0/), which permits unrestricted use, distribution, and reproduction in any medium, provided you give appropriate credit to the original author(s) and the source, provide a link to the Creative Commons license, and indicate if changes were made. 
Throughout this paper, we work in the setting of hyperbolic spaces introduced by Kohlenbach [2].

A hyperbolic space [2] is a metric space $(X, d)$ together with a mapping $W: X^{2} \times[0,1] \rightarrow$ $X$ satisfying

$$
\begin{array}{ll}
\text { (W1) } & d(u, W(x, y, \alpha)) \leq \alpha d(u, x)+(1-\alpha) d(u, y), \\
\text { (W2) } & d(W(x, y, \alpha), W(x, y, \beta))=|\alpha-\beta| d(x, y), \\
\text { (W3) } & W(x, y, \alpha)=W(y, x,(1-\alpha)) \\
\text { (W4) } & d(W(x, z, \alpha), W(y, w, \alpha)) \leq \alpha d(x, y)+(1-\alpha) d(z, w)
\end{array}
$$

for all $x, y, z, w \in X$ and $\alpha, \beta \in[0,1]$.

The class of hyperbolic spaces in the sense of Kohlenbach [2] contains all normed linear spaces and convex subsets thereof as well as Hadamard manifolds and CAT(0) spaces in the sense of Gromov. An important example of a hyperbolic space due to Goebel and Reich [4] is stated as follows.

Let $B_{H}$ be the open unit ball in a general complex Hilbert space $(H,\langle\cdot, \cdot\rangle)$ and let $k_{B_{H}}$ be a metric on $B_{H}$ (also known as Kobayashi distance) defined as

$$
k_{B_{H}}(x, y):=\tanh ^{-1}(1-\sigma(x, y))^{\frac{1}{2}}
$$

where

$$
\sigma(x, y)=\frac{\left(1-\|x\|^{2}\right)\left(1-\|y\|^{2}\right)}{|1-\langle x, y\rangle|^{2}} \quad \text { for all } x, y \in B_{H} .
$$

The open unit ball $B_{H}$ together with the metric $k_{B_{H}}$ is coined as a Hilbert ball. Since $\left(B_{H}, k_{B_{H}}\right)$ is a unique geodesic space, one can define a convexity mapping $W$ for the corresponding hyperbolic space $\left(B_{H}, k_{B_{H}}, W\right)$. This space is of significant importance for the fixed point theory of holomorphic mappings as the said class of mappings is $k_{B_{H}}$ nonexpansive in $\left(B_{H}, k_{B_{H}}, W\right)$. A metric space $(X, d)$ satisfying only (W1) is a convex metric space introduced by Takahashi [7]. A subset $K$ of a hyperbolic space $X$ is convex if $W(x, y, \alpha) \in K$ for all $x, y \in K$ and $\alpha \in[0,1]$. For more on hyperbolic spaces and a comparison between different notions of hyperbolic spaces in the current literature, we refer to [2], p.384.

It is worth to mention that the fixed point theory of nonexpansive mappings (i.e., $d(T x, T y) \leq d(x, y)$ for $x, y \in K)$ and its various generalizations majorly depends on the geometrical characteristics of the underlying space. The class of nonexpansive mappings enjoys the fixed point property (FPP) and the approximate fixed point property (AFPP) in various settings of spaces, see for example [8] for the later property for the class of nonexpansive mappings. Moreover, it is natural to extend such powerful results to generalized nonexpansive mappings as a mean of testing the limit of the theory of nonexpansive mappings. It is remarked that the FPP and even AFPP, in a nonlinear domain, of various generalizations of nonexpansive mappings are still developing. The class of hyperbolic spaces is endowed with rich geometric structures for different results with applications in topology, graph theory, multivalued analysis and metric fixed point theory. An important ingredient for metric fixed point theory of nonexpansive mappings is uniform convexity. 
A hyperbolic space $(X, d, W)$ is uniformly convex [9] if for all $u, x, y \in X, r>0$, and $\varepsilon \in$ $(0,2]$, there exists $\delta \in(0,1]$ such that

$$
d\left(W\left(x, y, \frac{1}{2}\right), u\right) \leq(1-\delta) r
$$

whenever $d(x, u) \leq r, d(y, u) \leq r$ and $d(x, y) \geq r \varepsilon$.

A mapping $\eta:(0, \infty) \times(0,2] \rightarrow(0,1]$ providing such $\delta=\eta(r, \varepsilon)$ for given $r>0$ and $\varepsilon \in$ $(0,2]$ is called modulus of uniform convexity. We call $\eta$ monotone if it decreases with $r$ (for a fixed $\varepsilon$ ), i.e., $\forall \varepsilon>0, \forall r_{2} \geq r_{1}>0\left(\eta\left(r_{2}, \varepsilon\right) \leq \eta\left(r_{1}, \varepsilon\right)\right)$. The CAT(0) spaces are uniformly convex hyperbolic spaces with modulus of uniform convexity $\eta(r, \varepsilon)=\frac{\varepsilon^{2}}{8}$ [9]. Therefore, the class of uniformly convex hyperbolic spaces includes CAT(0) spaces as a special case.

Metric fixed point theory of nonlinear mappings in a general setup of hyperbolic spaces is a fascinating field of research in nonlinear functional analysis. Moreover, iteration schemas are the only main tool to study fixed point problems of nonexpansive mappings and its various generalizations in spaces of non-positive sectional curvature. In 2006, Alber et al. [10] introduced a unified and generalized notion of a class of nonlinear mappings in Banach spaces, which can be introduced in the general setup of hyperbolic spaces as follows.

A self-mapping $T: K \rightarrow K$ is called (1) an asymptotically nonexpansive mapping if there exists a nonnegative real sequence $\left\{k_{n}\right\}$ with $k_{n} \rightarrow 0$ such that

$$
d\left(T^{n} x, T^{n} y\right) \leq d(x, y)+k_{n} d(x, y) \text { for all } x, y \in K, n \geq 1
$$

and (2) total asymptotically nonexpansive mapping if there exists nonnegative real sequences $\left\{k_{n}\right\}$ and $\left\{\varphi_{n}\right\}$ with $k_{n} \rightarrow 0$ and $\varphi_{n} \rightarrow 0$ as $n \rightarrow \infty$ and a strictly increasing continuous function $\xi: \mathbb{R}^{+} \rightarrow \mathbb{R}^{+}$with $\xi(0)=0$ such that

$$
d\left(T^{n} x, T^{n} y\right) \leq d(x, y)+k_{n} \xi(d(x, y))+\varphi_{n} \quad \text { for all } x, y \in K, n \geq 1
$$

\section{Example 1.1}

(i) Let $X=\mathbb{R}, K=[0, \infty)$ and $T: K \rightarrow K$ be defined by $T x=\sin x$. Then $T$ is a total asymptotically nonexpansive.

(ii) Let $X=\mathbb{R}, K=\left[-\frac{1}{\pi}, \frac{1}{\pi}\right]$ and $T: K \rightarrow K$ be defined by $T x=k x \sin \frac{1}{x}$, where $k \in(0,1)$. Then $T$ is a total asymptotically nonexpansive.

(iii) Let $K=\left\{x:=\left(x_{1}, x_{2}, \ldots, x_{n}, \ldots\right) \mid x_{1} \leq 0, x_{i} \in \mathbb{R}, i \geq 2\right\}$ be a nonempty subset of $X=l^{2}$ with the norm $\|\cdot\|$ defined as

$$
\|x\|=\sqrt{\sum_{i=1}^{\infty} x_{i}^{2}} .
$$

If $T: K \rightarrow K$ is defined by

$$
T(x)=\left(0,4 x_{2}, 0,0,0, \ldots\right)
$$

then $T$ is an asymptotically nonexpansive. 
(iv) Let $X=\mathbb{R}$ and $K=[0,2]$. Let $T: K \rightarrow K$ be a mapping defined by

$$
T(x)= \begin{cases}1, & x \in[0,1] \\ \frac{1}{\sqrt{3}} \sqrt{4-x^{2}}, & x \in[1,2] .\end{cases}
$$

Then $T$ is a total asymptotically nonexpansive mapping with $F(T)=\{1\}$. However, $T$ is not a Lipschitzian and hence it is not an asymptotically nonexpansive mapping.

The class of total asymptotically nonexpansive mappings and asymptotically nonexpansive mappings have been studied extensively in the literature [11-16] and the references cited therein. It is worth mentioning that the results established for total asymptotically nonexpansive mappings are applicable to the mappings associated with the class of asymptotically nonexpansive mappings and which are extensions of nonexpansive mappings.

It is remarked that the iterative construction of common fixed points of a finite family of asymptotically quasi-nonexpansive mappings in a Banach space through higher arity of an iteration is essentially due to Khan et al. [17] (see also [18] for the case of nonexpansive mappings). This iteration was further generalized by Khan and Ahmad [19] and Khan et al. [20] to the setup of convex metric spaces and CAT(0) spaces, respectively. Moreover, Chidume and Ofoedu [1] introduced a general iteration scheme for a finite family of total asymptotically nonexpansive mappings in Banach spaces, which we adopt in the setting of hyperbolic spaces as follows:

$$
\begin{aligned}
& x_{1} \in K, \\
& x_{n+1}=W\left(x_{n}, T_{1}^{n} x_{n}, \alpha_{n}\right) \quad \text { if } m=1, n \geq 1, \\
& x_{1} \in K, \\
& x_{n+1}=W\left(x_{n}, T_{1}^{n} y_{1 n}, \alpha_{n}\right), \\
& y_{1 n}=W\left(x_{n}, T_{2}^{n} y_{2 n}, \alpha_{n}\right), \\
& y_{2 n}=W\left(x_{n}, T_{3}^{n} y_{3 n}, \alpha_{n}\right), \\
& \ldots, \\
& y_{(m-2) n}=W\left(x_{n}, T_{m-1}^{n} y_{(m-1) n}, \alpha_{n}\right), \\
& y_{(m-1) n}=W\left(x_{n}, T_{m}^{n} x_{n}, \alpha_{n}\right) \quad \text { if } m \geq 2, n \geq 1,
\end{aligned}
$$

where $\left\{\alpha_{n}\right\}_{n=1}^{\infty}$ is a sequence in $[0,1]$ bounded away from 0 and 1 .

The purpose of this paper is to establish a fixed point result for a total asymptotically nonexpansive mapping along with the iterative construction of common fixed point of a finite family of these mappings in uniformly convex hyperbolic spaces. We therefore establish results concerning strong convergence and $\Delta$-convergence results of iteration (1.1). Our convergence results can be viewed not only as an analog of various existing results but also improve and generalize various results in the current literature.

\section{Preliminaries and some auxiliary lemmas}

We start this section with the notion of asymptotic center - essentially due to Edelstein [21] - of a sequence which is not only useful in proving a fixed point result but also plays 
a key role to define the concept of $\triangle$-convergence in hyperbolic spaces. In 1976, Lim [22] introduced the concept of $\triangle$-convergence in the general setting of metric spaces. In 2008, Kirk and Panyanak [23] further analyzed this concept in geodesic spaces. They showed that many Banach space results involving weak convergence have a precise analog version of $\triangle$-convergence in geodesic spaces.

Let $\left\{x_{n}\right\}$ be a bounded sequence in a hyperbolic space $X$. For $x \in X$, define a continuous functional $r\left(\cdot,\left\{x_{n}\right\}\right): X \rightarrow[0, \infty)$ by

$$
r\left(x,\left\{x_{n}\right\}\right)=\limsup _{n \rightarrow \infty} d\left(x, x_{n}\right)
$$

The asymptotic radius and asymptotic center of the bounded sequence $\left\{x_{n}\right\}$ with respect to a subset $K$ of $X$ is defined and denoted thus:

$$
r_{K}\left(\left\{x_{n}\right\}\right)=\inf \left\{r\left(x,\left\{x_{n}\right\}\right): x \in K\right\}
$$

and

$$
A_{K}\left(\left\{x_{n}\right\}\right)=\left\{x \in K: r\left(x,\left\{x_{n}\right\}\right) \leq r\left(y,\left\{x_{n}\right\}\right) \text { for all } y \in K\right\},
$$

respectively.

Recall that a sequence $\left\{x_{n}\right\}$ in $X$ is said to $\Delta$-converge to $x \in X$ if $x$ is the unique asymptotic center of $\left\{u_{n}\right\}$ for every subsequence $\left\{u_{n}\right\}$ of $\left\{x_{n}\right\}$. In this case, we write $\Delta-\lim _{n} x_{n}=x$ and call $x$ the $\triangle$-limit of $\left\{x_{n}\right\}$.

A mapping $T: K \rightarrow K$ is semi-compact if every bounded sequence $\left\{x_{n}\right\} \subset K$ satisfying $\lim _{n \rightarrow \infty} d\left(x_{n}, T x_{n}\right)=0$, has a convergent subsequence.

We now list some useful lemmas as well as establish some auxiliary results required in the sequel.

Lemma 2.1 ([24]) Let $(X, d, W)$ be a complete uniformly convex hyperbolic space with monotone modulus of uniform convexity $\eta$. Then every bounded sequence $\left\{x_{n}\right\}$ in $X$ has a unique asymptotic center with respect to any nonempty closed convex subset $K$ of $X$.

Proposition 2.2 ([25]) Let $(X, d, W)$ be a complete uniformly convex hyperbolic space with monotone modulus of uniform convexity $\eta$. The intersection of any decreasing sequence of nonempty bounded closed convex subsets of $X$ is nonempty.

Lemma 2.3 ([26]) Let $\left\{a_{n}\right\},\left\{b_{n}\right\}$, and $\left\{c_{n}\right\}$ be sequences of nonnegative real numbers such that $\sum_{n=1}^{\infty} b_{n}<\infty$ and $\sum_{n=1}^{\infty} c_{n}<\infty$. If $a_{n+1} \leq\left(1+b_{n}\right) a_{n}+c_{n}, n \geq 1$, then $\lim _{n \rightarrow \infty} a_{n}$ exists.

Lemma 2.4 ([27]) Let $(X, d, W)$ be a uniformly convex hyperbolic space with monotone modulus of uniform convexity $\eta$. Let $x \in X$ and $\left\{\alpha_{n}\right\}$ be a sequence in $[a, b]$ for some $a, b \in(0,1)$. If $\left\{x_{n}\right\}$ and $\left\{y_{n}\right\}$ are sequences in $X$ such that $\lim _{\sup _{n \rightarrow \infty}} d\left(x_{n}, x\right) \leq c$, $\limsup _{n \rightarrow \infty} d\left(y_{n}, x\right) \leq c$ and $\lim _{n \rightarrow \infty} d\left(W\left(x_{n}, y_{n}, \alpha_{n}\right), x\right)=c$ for some $c \geq 0$, then $\lim _{n \rightarrow \infty} d\left(x_{n}, y_{n}\right)=0$.

Lemma 2.5 ([27]) Let $K$ be a nonempty, closed, and convex subset of a uniformly convex hyperbolic space $X$ and $\left\{x_{n}\right\}$ a bounded sequence in $K$ such that $A_{K}\left(\left\{x_{n}\right\}\right)=\{y\}$ and $r_{K}\left(\left\{x_{n}\right\}\right)=\rho$. If $\left\{y_{m}\right\}$ is another sequence in $K$ such that $\lim _{m \rightarrow \infty} r\left(y_{m},\left\{x_{n}\right\}\right)=\rho$, then $\lim _{m \rightarrow \infty} y_{m}=y$. 
Lemma 2.6 Let $K$ be a nonempty, closed, and convex subset of a hyperbolic space $X$ and let $\left\{T_{i}\right\}_{i=1}^{m}: K \rightarrow K$ be a finite family of total asymptotically nonexpansive mappings with sequences $\left\{k_{i n}\right\}$ and $\left\{\varphi_{i n}\right\}, n \geq 1, i=1,2, \ldots$, m such that $F=\bigcap_{i=1}^{m} F\left(T_{i}\right) \neq \phi$. For $i=1,2, \ldots, m$ if the following conditions are satisfied:

(C1) $\sum_{n=1}^{\infty} k_{i n}<\infty$ and $\sum_{n=1}^{\infty} \varphi_{\text {in }}<\infty$;

(C2) there exist constants $M_{i}, M_{i}^{*}>0$ such that $\xi_{i}\left(\lambda_{i}\right) \leq M_{i}^{*} \lambda_{i}$ for all $\lambda_{i} \geq M_{i}$, $i=1,2,3, \ldots, m$,

then the sequence $\left\{x_{n}\right\}$ given by $(1.1)$ is bounded and $\lim _{n \rightarrow \infty} d\left(x_{n}, p\right)$ exists for each $p \in F$.

Proof Let $p \in F$ and $m=1$ in (1.1), we have

$$
\begin{aligned}
d\left(x_{n+1}, p\right) & =d\left(W\left(x_{n}, T_{1}^{n} x_{n}, \alpha_{n}\right), p\right) \\
& \leq\left(1-\alpha_{n}\right) d\left(x_{n}, p\right)+\alpha_{n} d\left(T_{1}^{n} x_{n}, p\right) \\
& \leq\left(1-\alpha_{n}\right) d\left(x_{n}, p\right)+\alpha_{n}\left\{d\left(x_{n}, p\right)+k_{1 n} \xi_{1}\left(d\left(x_{n}, p\right)\right)+\varphi_{1 n}\right\} \\
& \leq d\left(x_{n}, p\right)+b k_{1 n} \xi_{1}\left(d\left(x_{n}, p\right)\right)+b \varphi_{1 n},
\end{aligned}
$$

where $\alpha_{n} \leq b$ for some $b>0$.

Since $\xi_{1}$ is an increasing function, $\xi\left(d\left(x_{n}, p\right)\right) \leq \xi\left(M_{1}\right)$ for $d\left(x_{n}, p\right) \leq M_{1}$. Moreover, $\xi\left(d\left(x_{n}, p\right)\right) \leq d\left(x_{n}, p\right) M_{1}^{*}$ for $d\left(x_{n}, p\right) \geq M_{1}$ (by (C2)). In either case, we have

$$
\xi\left(d\left(x_{n}, p\right)\right) \leq \xi\left(M_{1}\right)+d\left(x_{n}, p\right) M_{1}^{*},
$$

where $M_{1}, M_{1}^{*}>0$.

Utilizing (2.2) in (2.1), we have

$$
d\left(x_{n+1}, p\right) \leq d\left(x_{n}, p\right)+b k_{1 n} \xi_{1}\left(M_{1}\right)+b k_{1 n} M_{1}^{*} d\left(x_{n}, p\right)+b \varphi_{1 n} .
$$

On setting $a_{1}=\max \left\{b, b M_{1}^{*}, b \xi_{1}\left(M_{1}\right)\right\}>0$, the above inequality becomes

$$
\begin{aligned}
d\left(x_{n+1}, p\right) & \leq d\left(x_{n}, p\right)+a_{1} k_{1 n}+a_{1} k_{1 n} d\left(x_{n}, p\right)+a_{1} \varphi_{1 n} \\
& =\left(1+a_{1} k_{1 n}\right) d\left(x_{n}, p\right)+a_{1} k_{1 n}+a_{1} \varphi_{1 n} .
\end{aligned}
$$

If $m=2$ in (1.1), we have the following iteration scheme:

$$
\begin{aligned}
& x_{1} \in K, \\
& x_{n+1}=W\left(x_{n}, T_{1}^{n} y_{1 n}, \alpha_{n}\right), \\
& y_{1 n}=W\left(x_{n}, T_{2}^{n} x_{n}, \alpha_{n}\right) .
\end{aligned}
$$

In view of the above iteration scheme, we have the following estimates:

$$
\begin{aligned}
d\left(x_{n+1}, p\right) & =d\left(W\left(x_{n}, T_{1}^{n} y_{1 n}, \alpha_{n}\right), p\right) \\
& \leq\left(1-\alpha_{n}\right) d\left(x_{n}, p\right)+\alpha_{n} d\left(T_{1}^{n} y_{1 n}, p\right) \\
& \leq\left(1-\alpha_{n}\right) d\left(x_{n}, p\right)+\alpha_{n}\left\{d\left(y_{1 n}, p\right)+k_{1 n} \xi_{1}\left(d\left(y_{1 n}, p\right)\right)+\varphi_{1 n}\right\}
\end{aligned}
$$


and

$$
\begin{aligned}
d\left(y_{1 n}, p\right) & =d\left(W\left(x_{n}, T_{2}^{n} x_{n}, \alpha_{n}\right), p\right) \\
& \leq\left(1-\alpha_{n}\right) d\left(x_{n}, p\right)+\alpha_{n} d\left(T_{2}^{n} x_{n}, p\right) \\
& \leq\left(1-\alpha_{n}\right) d\left(x_{n}, p\right)+\alpha_{n}\left\{d\left(x_{n}, p\right)+k_{2 n} \xi_{2}\left(d\left(x_{n}, p\right)\right)+\varphi_{2 n}\right\} .
\end{aligned}
$$

Again, we follow the method of proof as discussed for $m=1$.

In the light of $(\mathrm{C} 2)$ and the increasing functions $\xi_{i}(i=1,2)$, there exist $M_{i}, M_{i}^{*}>0(i=$ $1,2)$ such that

$$
\xi_{1}\left(d\left(y_{1 n}, p\right)\right) \leq \xi_{1}\left(M_{1}\right)+d\left(y_{1 n}, p\right) M_{1}^{*}
$$

and

$$
\xi_{2}\left(d\left(x_{n}, p\right)\right) \leq \xi_{2}\left(M_{2}\right)+d\left(x_{n}, p\right) M_{2}^{*} .
$$

Substituting (2.5) in (2.3) and (2.6) in (2.4), we get

$$
\begin{aligned}
d\left(x_{n+1}, p\right) \leq & \left(1-\alpha_{n}\right) d\left(x_{n}, p\right)+\alpha_{n}\left\{d\left(y_{1 n}, p\right)+k_{1 n} \xi_{1}\left(d\left(y_{1 n}, p\right)\right)+\varphi_{1 n}\right\} \\
\leq & \left(1-\alpha_{n}\right) d\left(x_{n}, p\right)+\alpha_{n} d\left(y_{1 n}, p\right)+\alpha_{n} k_{1 n} \xi_{1}\left(M_{1}\right) \\
& +\alpha_{n} k_{1 n} d\left(y_{1 n}, p\right) M_{1}^{*}+\alpha_{n} \varphi_{n} \\
= & \left(1-\alpha_{n}\right) d\left(x_{n}, p\right)+\alpha_{n}\left(1+k_{1 n} M_{1}^{*}\right) d\left(y_{1 n}, p\right)+\alpha_{n} k_{1 n} \xi_{1}\left(M_{1}\right)+\alpha_{n} \varphi_{n}
\end{aligned}
$$

and

$$
\begin{aligned}
d\left(y_{1 n}, p\right) & =d\left(W\left(x_{n}, T_{2}^{n} x_{n}, \alpha_{n}\right), p\right) \\
& \leq\left(1-\alpha_{n}\right) d\left(x_{n}, p\right)+\alpha_{n} d\left(T_{2}^{n} x_{n}, p\right) \\
& \leq\left(1-\alpha_{n}\right) d\left(x_{n}, p\right)+\alpha_{n}\left\{d\left(x_{n}, p\right)+k_{2 n}\left(\xi_{2}\left(d\left(x_{n}, p\right)\right)\right)+\varphi_{2 n}\right\} \\
& \leq\left(1-\alpha_{n}\right) d\left(x_{n}, p\right)+\alpha_{n}\left\{d\left(x_{n}, p\right)+k_{2 n}\left(\xi_{2}\left(M_{2}\right)+d\left(x_{n}, p\right) M_{2}^{*}\right)+\varphi_{2 n}\right\} \\
& =d\left(x_{n}, p\right)+\alpha_{n} k_{2 n} \xi_{2}\left(M_{2}\right)+\alpha_{n} k_{2 n} d\left(x_{n}, p\right) M_{2}^{*}+\alpha_{n} \varphi_{2 n} .
\end{aligned}
$$

Putting (2.8) in (2.7), we have

$$
\begin{aligned}
d\left(x_{n+1}, p\right) \leq & \left(1-\alpha_{n}\right) d\left(x_{n}, p\right)+\alpha_{n}\left(1+k_{1 n} M_{1}^{*}\right)\left[d\left(x_{n}, p\right)+\alpha_{n} k_{2 n} \xi_{2}\left(M_{2}\right)\right. \\
& \left.+\alpha_{n} k_{2 n} d\left(x_{n}, p\right) M_{2}^{*}+\alpha_{n} \varphi_{2 n}\right]+\alpha_{n} k_{1 n} \xi_{1}\left(M_{1}\right)+\alpha_{n} \varphi_{1 n} \\
= & \left(1+\alpha_{n} k_{1 n} M_{1}^{*}+\alpha_{n}^{2} k_{2 n} M_{2}^{*}+\alpha_{n}^{2} k_{1 n} k_{2 n} M_{1}^{*} M_{2}^{*}\right) d\left(x_{n}, p\right) \\
& +\alpha_{n}\left(1+k_{1 n} M_{1}^{*}\right)\left[\alpha_{n} k_{2 n} \xi_{2}\left(M_{2}\right)+\alpha_{n} \varphi_{2 n}\right] \\
& +\alpha_{n} k_{1 n} \xi_{1}\left(M_{1}\right)+\alpha_{n} \varphi_{1 n} \\
\leq & \left(1+\alpha_{n} k_{1 n} M_{1}^{*}+\alpha_{n} k_{2 n} M_{2}^{*}+\alpha_{n} k_{1 n} k_{2 n} M_{1}^{*} M_{2}^{*}\right) d\left(x_{n}, p\right) \\
& +\alpha_{n} k_{2 n} \xi_{2}\left(M_{2}\right)+\alpha_{n} k_{1 n} k_{2 n} M_{1}^{*} \xi_{2}\left(M_{2}\right) \\
& +\alpha_{n} \varphi_{2 n}+\alpha_{n} k_{1 n} \varphi_{2 n} M_{1}^{*}+\alpha_{n} k_{1 n} \xi_{1}\left(M_{1}\right)+\alpha_{n} \varphi_{1 n} .
\end{aligned}
$$


Again $\alpha_{n} \leq b$ for all $n \geq 1$. Further we can bound the convergent sequences $\left\{k_{1 n}\right\},\left\{k_{2 n}\right\}$, and $\left\{\varphi_{2 n}\right\}$ as $k_{1 n} \leq c_{1}, k_{2 n} \leq c_{2}$, and $\varphi_{2 n} \leq d_{2}$ for all $n \geq 1$.

Utilizing these bounds, the above estimate becomes

$$
\begin{aligned}
d\left(x_{n+1}, p\right) \leq & {\left[1+b k_{1 n} M_{1}^{*}+\left(b M_{2}^{*}+b c_{1} M_{1}^{*} M_{2}^{*}\right) k_{2 n}\right] d\left(x_{n}, p\right) } \\
& +b \xi_{2}\left(M_{2}\right) k_{2 n}+b c_{2} M_{1}^{*} \xi_{2}\left(M_{2}\right) k_{1 n} \\
& +b \varphi_{2 n}+b c_{1} M_{1}^{*} \varphi_{2 n}+b k_{1 n} \xi_{1}\left(M_{1}\right)+b \varphi_{1 n} \\
= & {\left[1+b M_{1}^{*} k_{1 n}+b\left(M_{2}^{*}+c_{1} M_{1}^{*} M_{2}^{*}\right) k_{2 n}\right] d\left(x_{n}, p\right) } \\
& +b\left(c_{2} M_{1}^{*} \xi_{2}\left(M_{2}\right)+\xi_{1}\left(M_{1}\right)\right) k_{1 n}+b \xi_{2}\left(M_{2}\right) k_{2 n} \\
& +b \varphi_{1 n}+b\left(1+c_{1} M_{1}^{*}\right) \varphi_{2 n} .
\end{aligned}
$$

That is,

$$
d\left(x_{n+1}, p\right) \leq\left(1+\left(k_{1 n}+k_{2 n}\right) a_{2}\right) d\left(x_{n}, p\right)+\left(k_{2 n}+k_{1 n}+\varphi_{2 n}+\varphi_{1 n}\right) a_{2},
$$

where

$$
\begin{aligned}
a_{2} & =\max \left\{b, b M_{1}^{*}, b\left(1+c_{1}\right) M_{1}^{*}, b\left(M_{2}^{*}+c_{1} M_{1}^{*} M_{2}^{*}\right), b\left(c_{2} M_{1}^{*} \xi_{2}\left(M_{2}\right)+\xi_{1}\left(M_{1}\right)\right), b \xi_{2}\left(M_{2}\right)\right\} \\
& >0 .
\end{aligned}
$$

That is,

$$
d\left(x_{n+1}, p\right) \leq\left(1+a_{2} \sum_{j=1}^{2} k_{j n}\right) d\left(x_{n}, p\right)+a_{2} \sum_{j=1}^{2}\left(k_{j n}+\varphi_{j n}\right) .
$$

Continuing in a similar fashion for any $m \geq 1$, we have the following compact form of the above estimate:

$$
d\left(x_{n+1}, p\right) \leq\left(1+a_{m} \sum_{j=1}^{m} k_{j n}\right) d\left(x_{n}, p\right)+a_{m} \sum_{j=1}^{m}\left(k_{j n}+\varphi_{j n}\right)
$$

for some constant $a_{m}>0$.

Appealing to Lemma 2.3, the above inequality implies that $\lim _{n \rightarrow \infty} d\left(x_{n}, p\right)$ exists and hence the sequence $\left\{x_{n}\right\}$ is bounded.

Lemma 2.7 Let $K$ be a nonempty, closed, and convex subset of a uniformly convex hyperbolic space $X$ with monotone modulus of uniform convexity $\eta$ and let $\left\{T_{i}\right\}_{i=1}^{m}: K \rightarrow K$ be a finite family of uniformly continuous total asymptotically nonexpansive mappings with sequences $\left\{k_{i n}\right\}$ and $\left\{\varphi_{\text {in }}\right\}, n \geq 1, i=1,2, \ldots$, m such that $F:=\bigcap_{i=1}^{m} F\left(T_{i}\right) \neq \phi$. For $i=1,2, \ldots, m$, if the following conditions are satisfied:

(C1) $\sum_{n=1}^{\infty} k_{i n}<\infty$ and $\sum_{n=1}^{\infty} \varphi_{i n}<\infty$;

(C2) there exist constants $M_{i}, M_{i}^{*}>0$ such that $\xi_{i}\left(\lambda_{i}\right) \leq M_{i}^{*} \lambda_{i}$ for all $\lambda_{i} \geq M_{i}$, then for the sequence $\left\{x_{n}\right\}$ given by (1.1), we have $\lim _{n \rightarrow \infty} d\left(x_{n}, T_{i} x_{n}\right)=0, i=1,2, \ldots, m$. 
Proof It follows from Lemma 2.6 that $\lim _{n \rightarrow \infty} d\left(x_{n}, p\right)$ exists. Without loss of generality, we can assume that $\lim _{n \rightarrow \infty} d\left(x_{n}, p\right)=r>0$. We first distinguish two cases to show that $\lim _{n \rightarrow \infty} d\left(x_{n}, T_{i}^{n} x_{n}\right)=0, i=1,2, \ldots, m$.

Case 1 . For $m=1$, we proceed as follows:

$$
\lim _{n \rightarrow \infty} d\left(W\left(x_{n}, T_{1}^{n} x_{n}, \alpha_{n}\right), p\right)=\lim _{n \rightarrow \infty} d\left(x_{n+1}, p\right)=r
$$

It follows from the total asymptotically nonexpansiveness of $T_{1}$, that is,

$$
\begin{aligned}
d\left(T_{1}^{n} x_{n}, p\right) & =d\left(T_{1}^{n} x_{n}, T_{1}^{n} p\right) \leq d\left(x_{n}, p\right)+k_{1 n} \xi_{1}\left(d\left(x_{n}, p\right)\right)+\varphi_{1 n} \\
& \leq d\left(x_{n}, p\right)+k_{1 n} M_{1}^{*} d\left(x_{n}, p\right)+k_{1 n} \xi_{1}\left(M_{1}\right)+\varphi_{1 n} \\
& =\left(1+k_{1 n} M_{1}^{*}\right) d\left(x_{n}, p\right)+k_{1 n} \xi_{1}\left(M_{1}\right)+\varphi_{1 n} .
\end{aligned}
$$

Taking limsup on both sides of the above estimate and utilizing the fact that $k_{1 n} \rightarrow 0$ and $\varphi_{1 n} \rightarrow 0$ as $n \rightarrow \infty$, we get

$$
\limsup _{n \rightarrow \infty} d\left(T_{1}^{n} x_{n}, p\right) \leq r
$$

Moreover, $\limsup _{n \rightarrow \infty} d\left(x_{n}, p\right)=r$. Hence, the conclusion, i.e., $\lim _{n \rightarrow \infty} d\left(T_{1}^{n} x_{n}, x_{n}\right)=0$ follows from Lemma 2.4.

Case 2. For $m=2$, the iteration (1.1) reduces to

$$
\begin{aligned}
& x_{n+1}=W\left(x_{n}, T_{1}^{n} y_{1 n}, \alpha_{n}\right), \\
& y_{1 n}=W\left(x_{n}, T_{2}^{n} x_{n}, \alpha_{n}\right) .
\end{aligned}
$$

As calculated in Lemma 2.6, we have

$$
\begin{aligned}
d\left(y_{1 n}, p\right) & =d\left(W\left(x_{n}, T_{2}^{n} x_{n}, \alpha_{n}\right), p\right) \\
& \leq\left(1+k_{2 n} M_{2}^{*}\right) d\left(x_{n}, p\right)+\alpha_{n} k_{2 n} \xi_{2}\left(M_{2}\right)+\alpha_{n} \varphi_{2 n} .
\end{aligned}
$$

Taking lim sup on both sides in the above estimate, we have

$$
\limsup _{n \rightarrow \infty} d\left(y_{1 n}, p\right) \leq r
$$

Now observe that

$$
d\left(T_{1}^{n} y_{1 n}, p\right) \leq\left(1+k_{1 n} M_{1}^{*}\right) d\left(y_{1 n}, p\right)+k_{1 n} \xi_{1}\left(M_{1}\right)+\varphi_{1 n} .
$$

Taking lim sup on both sides of the above estimate and utilizing (2.10), we get

$$
\limsup _{n \rightarrow \infty} d\left(T_{1}^{n} y_{1 n}, p\right) \leq r
$$

Since $\lim \sup _{n \rightarrow \infty} d\left(x_{n}, p\right) \leq r$, it follows from (2.11) and Lemma 2.4 that

$$
\lim _{n \rightarrow \infty} d\left(x_{n}, T_{1}^{n} y_{1 n}\right)=0 .
$$


Observe that

$$
\begin{aligned}
d\left(x_{n}, p\right) & \leq d\left(x_{n}, T_{1}^{n} y_{1 n}\right)+d\left(T_{1}^{n} y_{1 n}, p\right) \\
& \leq d\left(x_{n}, T_{1}^{n} y_{1 n}\right)+\left(1+k_{1 n} M_{1}^{*}\right) d\left(y_{1 n}, p\right)+k_{1 n} \xi_{1}\left(M_{1}\right)+\varphi_{1 n} .
\end{aligned}
$$

Hence, we deduce from the above estimate that

$$
r \leq \liminf _{n \rightarrow \infty} d\left(y_{1 n}, p\right)
$$

The estimates (2.10) and (2.13) collectively imply that

$$
\lim _{n \rightarrow \infty} d\left(y_{1 n}, p\right)=d\left(W\left(x_{n}, T_{2}^{n} x_{n}, \alpha_{n}\right), p\right)=r .
$$

Utilizing the total asymptotically nonexpansiveness of $T_{2}$ and the fact that $k_{2 n} \rightarrow 0, \varphi_{2 n} \rightarrow$ 0 as $n \rightarrow \infty$, we have

$$
\limsup _{n \rightarrow \infty} d\left(T_{2}^{n} x_{n}, p\right) \leq r
$$

Now (2.14), (2.15), and Lemma 2.4, imply that

$$
\lim _{n \rightarrow \infty} d\left(T_{2}^{n} x_{n}, x_{n}\right)=0
$$

With the help of $d\left(y_{1 n}, x_{n}\right) \leq \alpha_{n} d\left(T_{2}^{n} x_{n}, x_{n}\right) \leq b d\left(T_{2}^{n} x_{n}, x_{n}\right)$ and (2.16), we obtain

$$
\lim _{n \rightarrow \infty} d\left(y_{1 n}, x_{n}\right)=0 .
$$

It follows from (2.12) and (2.17) that

$$
\lim _{n \rightarrow \infty} d\left(y_{1 n}, T_{1}^{n} y_{1 n}\right)=0
$$

Moreover

$$
d\left(T_{1}^{n} x_{n}, x_{n}\right) \leq d\left(T_{1}^{n} x_{n}, T_{1}^{n} y_{1 n}\right)+d\left(T_{1}^{n} y_{1 n}, x_{n}\right) .
$$

Since $T_{1}$ is uniformly continuous, letting $n \rightarrow \infty$ in the above estimate and utilizing (2.12) and (2.17), we get

$$
\lim _{n \rightarrow \infty} d\left(T_{1}^{n} x_{n}, x_{n}\right)=0
$$

Hence

$$
\lim _{n \rightarrow \infty} d\left(T_{i}^{n} x_{n}, x_{n}\right)=0 \quad \text { for } i=1,2
$$

Continuing in a similar way, we get

$$
\lim _{n \rightarrow \infty} d\left(T_{i}^{n} x_{n}, x_{n}\right)=0 \quad \text { for } i=1,2, \ldots, m
$$


Now, utilizing the uniform continuity of $T_{i}$, the following estimate:

$$
d\left(x_{n}, T_{i} x_{n}\right) \leq d\left(x_{n}, T_{i}^{n} x_{n}\right)+d\left(T_{i}^{n} x_{n}, T_{i} x_{n}\right)
$$

implies that

$$
\lim _{n \rightarrow \infty} d\left(T_{i} x_{n}, x_{n}\right)=0 \quad \text { for } i=1,2, \ldots, m
$$

This completes the proof.

\section{Existence and convergence results}

In this section, we first establish the existence of fixed point of total asymptotically nonexpansive mapping. Our proof closely follows Theorem 3.3 in [25] for the existence of fixed point of asymptotically nonexpansive mappings in uniformly convex hyperbolic spaces.

Theorem 3.1 Let $(X, d, W)$ be a complete uniformly convex hyperbolic space having a monotone modulus of uniform convexity $\eta$. Let $K$ be a nonempty, bounded, closed, and convex subset of $X$. Then a continuous and total asymptotically nonexpansive mapping $T: K \rightarrow K$ has a fixed point.

Proof For any $y \in K$, define

$$
K_{y}=\left\{\tau \in \mathbb{R}^{+}: \text {there exists } x \in K, n_{0} \in \mathbb{N} \text { such that } d\left(T^{i} y, x\right) \leq \tau \text { for all } i \geq n_{0}\right\}
$$

It is easy to see that $K_{y}$ is nonempty as $\operatorname{diam}(K) \in K_{y}$. Let $\alpha_{y}:=\inf K_{y}$ then for any $\theta>0$, there exists $\tau_{\theta} \in K_{y}$ such that $\tau_{\theta}<\alpha_{y}+\theta$, so there exist $x \in K$ and $n_{0} \in \mathbb{N}$ such that

$$
d\left(T^{i} y, x\right) \leq \tau_{\theta}<\alpha_{y}+\theta \quad \text { for all } i \geq n_{0} .
$$

Obviously, $\alpha_{y} \geq 0$. Here, we distinguish two cases.

Case 1. $\alpha_{y}=0$. We show that the sequence $\left\{T^{i} y\right\}_{i=1}^{\infty}$ is Cauchy. Let $m, n \geq n_{0} \in \mathbb{N}$ and let $\varepsilon>0$, then applying (3.1) with $\theta=\frac{\varepsilon}{2}$, we get

$$
d\left(T^{m} y, T^{n} y\right) \leq d\left(T^{m} y, x\right)+d\left(T^{n} y, x\right)<\frac{\varepsilon}{2}+\frac{\varepsilon}{2}=\varepsilon .
$$

Hence $\left\{T^{i} y\right\}_{i=1}^{\infty}$ is Cauchy and consequently converges to some $z \in K$. Using the definition of $T$, choose $n_{1} \in \mathbb{N}$ such that

$$
\left\{\left(d\left(T^{i} z, T^{i} x\right)-d(z, x)-k_{i} \xi(d(z, x))-\varphi_{i}\right)\right\} \leq \frac{\varepsilon}{2} \quad \text { for all } i \geq n_{1} .
$$

Since $T^{i} y \rightarrow z$, this implies $d\left(T^{m} y, z\right), d\left(T^{m-i} y, z\right) \leq \frac{\varepsilon}{2}$ for all $m>i$. Thus, if $i \geq m$ then

$$
\begin{aligned}
d\left(z, T^{i} z\right) \leq & d\left(z, T^{m} y\right)+d\left(T^{m} y, T^{i} z\right) \\
\leq & d\left(z, T^{m} y\right)+\left(d\left(T^{i} z, T^{i}\left(T^{m-i} y\right)\right)-k_{i} \xi\left(d\left(T^{m-i} y, z\right)\right)-\varphi_{i}\right) \\
& +k_{i} \xi\left(d\left(T^{m-i} y, z\right)\right)+\varphi_{i}
\end{aligned}
$$




$$
\begin{aligned}
\leq & d\left(z, T^{m} y\right)+\left(d\left(T^{i} z, T^{i}\left(T^{m-i} y\right)\right)-k_{i} \xi\left(d\left(T^{m-i} y, z\right)\right)-\varphi_{i}\right) \\
& +k_{i} M^{*} d\left(T^{m-i} y, z\right)+\varphi_{i} \\
\leq & \varepsilon+k_{i} M^{*} \frac{\varepsilon}{2}+\varphi_{i},
\end{aligned}
$$

where $M^{*}>0$ such that $\xi(\lambda) \leq M^{*} \lambda$.

Letting $i \rightarrow \infty$ in the above estimate, we have $T^{i} z \rightarrow z$. Hence the continuity of $T$ implies that $z$ is a fixed point of $T$, i.e.,

$$
d(T z, z)=d\left(T\left(\lim _{i \rightarrow \infty} T^{i} z\right), z\right)=\lim _{i \rightarrow \infty} d\left(T\left(T^{i} z\right), z\right)=\lim _{i \rightarrow \infty} d\left(T^{i+1} z, z\right)=0 .
$$

So $T z=z$.

Case 2. $\alpha_{y}>0$. For any $n \geq 1$, we define

$$
C_{n}=\bigcup_{k \geq 1} \bigcap_{i \geq k} \bar{U}\left(T^{i} y, \alpha_{y}+\frac{1}{n}\right), \quad D_{n}:=\bar{C}_{n} \cap K .
$$

By (3.1) with $\theta=\frac{1}{n}$, there exist $x \in K$ and $k \geq 1$ such that $x \in \bigcap_{i \geq k} \bar{U}\left(T^{i} y, \alpha_{y}+\frac{1}{n}\right)$; hence $D_{n}$ is nonempty. Moreover, $\left\{D_{n}\right\}$ is a decreasing sequence of nonempty-bounded closed convex subsets of $X$, hence, we can apply Proposition 2.2 to derive that

$$
D:=\bigcap_{n \geq 1} D_{n} \neq \phi
$$

For any $x \in D$ and $\theta>0$, take $n^{*} \in \mathbb{N}$ such that $\frac{2}{n^{*}} \leq \theta$. Since $x \in \bar{C}_{n^{*}}$, there exists a sequence $\left\{x_{\left(n^{*}\right) n}\right\}$ in $C_{n^{*}}$ such that $\lim _{n \rightarrow \infty} x_{\left(n^{*}\right) n}=x$. Let $n^{\prime} \geq 1$ be such that $d\left(x_{\left(n^{*}\right) n}, x\right) \leq \frac{1}{n^{*}}$ for all $n \geq n^{\prime}$ and $s \geq 1$ such that $x_{\left(n^{*}\right) n^{\prime}} \in \bigcap_{i \geq s} \bar{U}\left(T^{i} y, \alpha_{y}+\frac{1}{n^{*}}\right)$. It follows that, for all $i \geq s$,

$$
d\left(T^{i} y, x\right) \leq d\left(T^{i} y, x_{\left(n^{*}\right) n^{\prime}}\right)+d\left(x_{\left(n^{*}\right) n^{\prime}}, x\right) \leq \alpha_{y}+\frac{1}{n^{*}}+\frac{1}{n^{*}} \leq \alpha_{y}+\theta .
$$

In the sequel, we shall prove that any point of $D$ is a fixed point of $T$. We assume toward contradiction that $T x \neq x$ for any $x \in D$. Then $T^{n} x \nrightarrow x$ (by Case 1 ), so there exist $\varepsilon>0$ and $\hat{n} \in \mathbb{N}$ such that

$$
d\left(T^{n} x, x\right) \geq \varepsilon \quad \text { for all } n \geq \hat{n} .
$$

We can assume that $\varepsilon \in(0,2]$ so that $\frac{\varepsilon}{\alpha_{y}+1} \in(0,2]$. Hence there exists $\theta_{y} \in(0,1]$ such that

$$
1-\eta\left(\alpha_{y}+1, \frac{\varepsilon}{\alpha_{y}+1}\right) \leq \frac{\alpha_{y}-\theta_{y}}{\alpha_{y}+\theta_{y}}
$$

Observe that $\lim _{n \rightarrow \infty}\left(\left(1+k_{n} M^{*}\right)\left(\alpha_{y}+\frac{\theta_{y}}{2}\right)+\varphi_{n}\right)=\alpha_{y}+\frac{\theta_{y}}{2}<\alpha_{y}+\theta_{y}$, so there exists $\tilde{n} \in \mathbb{N}$ such that

$$
\left(1+k_{n} M^{*}\right)\left(\alpha_{y}+\frac{\theta_{y}}{2}\right)+\varphi_{n}<\alpha_{y}+\theta_{y} \quad \text { for all } n \geq \tilde{n}
$$


Applying (3.2) with $\theta=\frac{\theta_{y}}{2}$, there exists $n^{* *} \in \mathbb{N}$ such that

$$
d\left(T^{i} y, x\right) \leq \alpha_{y}+\frac{\theta_{y}}{2} \quad \text { for all } i \geq n^{* *}
$$

By the definition of $T$, choose $n^{\prime \prime} \in \mathbb{N}$ such that

$$
\left\{\left(d\left(T^{m} z, T^{m} x\right)-d(z, x)-k_{n} \xi(d(z, x))-\varphi_{n}\right)\right\} \leq \frac{\theta_{y}}{2} \quad \text { for all } m \geq n^{\prime \prime}
$$

Applying (3.3) with $\hat{n}:=\tilde{n}$, we get

$$
d\left(T^{n^{*}} x, x\right) \geq \varepsilon \geq \frac{\varepsilon}{\alpha_{y}+1}\left(\alpha_{y}+\theta_{y}\right) \quad \text { for all } n^{*} \geq \tilde{n} .
$$

Let now $m \in \mathbb{N}$ be such that $m \geq n^{*}+n^{* *}$, then the estimate (3.5) implies that

$$
d\left(T^{m} y, x\right) \leq \alpha_{y}+\frac{\theta_{y}}{2}<\alpha_{y}+\theta_{y}
$$

Moreover, observe that

$$
\begin{aligned}
d\left(T^{n^{*}} x, T^{m} y\right) & =d\left(T^{n^{*}} x, T^{n^{*}}\left(T^{m-n^{*}} y\right)\right) \\
& \leq d\left(x, T^{m-n^{*}} y\right)+k_{n^{*}} \xi\left(d\left(x, T^{m-n^{*}} y\right)\right)+\varphi_{n^{*}} \\
& \leq d\left(x, T^{m-n^{*}} y\right)+k_{n^{*}} M^{*} d\left(x, T^{m-n^{*}} y\right)+\varphi_{n^{*}} \\
& \leq\left(1+k_{n^{*}} M^{*}\right)\left(\alpha_{y}+\frac{\theta_{y}}{2}\right)+\varphi_{n^{*}}
\end{aligned}
$$

Utilizing (3.4) in the above estimate, we get

$$
d\left(T^{n^{*}} x, T^{m} y\right)<\alpha_{y}+\theta_{y} .
$$

It follows from the estimates (3.6)-(3.8) and uniform convexity of $X$ that

$$
\begin{aligned}
d\left(W\left(x, T^{n^{*}} x, \frac{1}{2}\right), T^{m} y\right) & \leq\left(1-\eta\left(\alpha_{y}+\theta_{y}, \frac{\varepsilon}{\alpha_{y}+1}\right)\right)\left(\alpha_{y}+\theta_{y}\right) \\
& \leq\left(1-\eta\left(\alpha_{y}+1, \frac{\varepsilon}{\alpha_{y}+1}\right)\right)\left(\alpha_{y}+\theta_{y}\right) \quad(\eta \text { is monotone }) \\
& \leq\left(\frac{\alpha_{y}-\theta_{y}}{\alpha_{y}+\theta_{y}}\right)\left(\alpha_{y}+\theta_{y}\right)=\alpha_{y}-\theta_{y} .
\end{aligned}
$$

Hence, there exist $\hat{n}=n^{*}+n^{* *}$ and $z=W\left(x, T^{n^{*}} x, \frac{1}{2}\right) \in K$ such that

$$
d\left(z, T^{m} y\right) \leq \alpha_{y}-\theta_{y} \quad \text { for all } m \geq \hat{n}
$$

This implies that $\alpha_{y}-\theta_{y} \in K_{y}$, which contradicts the fact that $\alpha_{y}=\inf K_{y}$. Hence $x$ is a fixed point of $T$. This completes the proof.

We now use the concept of asymptotic center of a bounded sequence to strengthen the above existence result. The proof, in fact, follows closely the proof of Lemma 2.6 in [27]. 
Theorem 3.2 Let $(X, d, W)$ be a complete uniformly convex hyperbolic space having a monotone modulus of uniform convexity $\eta$. Let $K$ be a nonempty, closed, and convex subset of $X$ and let $T: K \rightarrow K$ be a continuous and total asymptotically nonexpansive mapping. If $\left\{T^{n} x\right\}$ is bounded for some $x \in K$ and $z \in A_{K}\left(\left\{T^{n} x\right\}\right)$, then $z$ is a fixed point of $T$.

Proof Let $\left\{T^{n} x\right\}$ be bounded and $z \in A_{K}\left(\left\{T^{n} x\right\}\right)$. It follows from Lemma 2.1 that $z$ is the unique asymptotic center of $\left\{T^{n} x\right\}$. Assume $y_{i}=T^{i} z \in K$. We show that $y_{i} \rightarrow z$ as $i \rightarrow \infty$. Contrarily, we assume that $y_{i} \nrightarrow z$, then there exist a subsequence $\left\{y_{i_{j}}\right\}$ of $\left\{y_{i}\right\}$ and $\alpha>0$ such that

$$
d\left(y_{i}, z\right) \geq \frac{\alpha}{2} \quad \text { for all } j
$$

Let $\mu=r_{K}\left(\left\{T^{n} x\right\}\right)$. For any $\varepsilon \in(0,1]$ there exists $N \in \mathbb{N}$ such that, for all $n \geq N$, we have

$$
d\left(y, T^{n} x\right) \leq \mu+\varepsilon \leq \mu+1 \quad \text { and } \quad d\left(y_{i j}, T^{n} x\right) \leq \mu+\varepsilon \leq \mu+1 .
$$

It follows from the uniform convexity that

$$
\begin{aligned}
d\left(W\left(y, y_{i j}, \frac{1}{2}\right), T^{n} x\right) & \leq\left(1-\eta\left(\mu+\varepsilon, \frac{\alpha}{2(\mu+1)}\right)\right)(\mu+\varepsilon) \\
& \leq\left(1-\eta\left(\mu+1, \frac{\alpha}{2(\mu+1)}\right)\right)(\mu+\varepsilon) .
\end{aligned}
$$

Note that when $n \rightarrow \infty$, then the above estimate implies that

$$
r\left(W\left(y, y_{i j}, \frac{1}{2}\right), T^{n} x\right) \leq\left(1-\eta\left(\mu+1, \frac{\alpha}{2(\mu+1)}\right)\right)(\mu+\varepsilon) .
$$

Since $\left(1-\eta\left(\mu+1, \frac{\alpha}{2(\mu+1)}\right)\right)(\mu+\varepsilon)<\mu$ when $\varepsilon \rightarrow 0$, from the above estimate

$$
r\left(W\left(y, y_{i j}, \frac{1}{2}\right), T^{n} x\right)<\mu .
$$

A contradiction to the fact that $\mu$ is the asymptotic radius of $\left\{T^{n} x\right\}$. Now, Lemma 2.5 implies that $y_{i} \rightarrow z$ as $i \rightarrow \infty$. The continuity of $T$ implies that $z$ is a fixed point of $T$. This completes the proof.

Remark 3.3 It is remarked that Theorems 3.1 and 3.2 can also be adopted to prove the existence of a common fixed point for a total asymptotically nonexpansive semigroup. A different approach to prove the existence of a common fixed point for such semigroups can be found in a recent paper due to Suantai and Phuengrattana [28].

The rest of the paper deals with the convergence analysis of iteration process (1.1) for the approximation of common fixed points of a finite family of total asymptotically nonexpansive mappings.

Theorem 3.4 Let $K$ be a nonempty, closed, and convex subset of a uniformly convex hyperbolic space $X$ with monotone modulus of uniform convexity $\eta$ and let $\left\{T_{i}\right\}_{i=1}^{m}: K \rightarrow K$ be a 
finite family of uniformly continuous total asymptotically nonexpansive mappings with sequences $\left\{k_{\text {in }}\right\}$ and $\left\{\varphi_{\text {in }}\right\}, n \geq 1, i=1,2, \ldots, m$, such that $F:=\bigcap_{i=1}^{m} F\left(T_{i}\right) \neq \phi$. For $i=1,2, \ldots, m$ if the following conditions are satisfied:

(C1) $\sum_{n=1}^{\infty} k_{i n}<\infty$ and $\sum_{n=1}^{\infty} \varphi_{i n}<\infty$;

(C2) there exist constants $M_{i}, M_{i}^{*}>0$ such that $\xi_{i}\left(\lambda_{i}\right) \leq M_{i}^{*} \lambda_{i}$ for all $\lambda_{i} \geq M_{i}$, then the sequence $\left\{x_{n}\right\}$ defined in (1.1) $\triangle$-converges to a point in $F$.

Proof It follows from Lemma 2.6 that $\left\{x_{n}\right\}$ is bounded. Therefore by Lemma 2.1, $\left\{x_{n}\right\}$ has a unique asymptotic center, that is, $A_{K}\left(\left\{x_{n}\right\}\right)=\{x\}$. Let $\left\{u_{n}\right\}$ be any subsequence of $\left\{x_{n}\right\}$ such that $A_{K}\left(\left\{u_{n}\right\}\right)=\{u\}$ and

$$
\lim _{n \rightarrow \infty} d\left(u_{n}, T_{i} u_{n}\right)=0 \quad \text { for all } i=1,2, \ldots, m .
$$

Next, we show that $u \in F$. For each $j \in\{1,2,3, \ldots, m\}$, we define a sequence $\left\{z_{n}\right\}$ in $K$ by $z_{i}=T_{j}^{i} u$. In the presence of the increasing function $\xi_{j}$ and (C2), we calculate

$$
\begin{aligned}
d\left(z_{i}, u_{n}\right) & \leq d\left(T_{j}^{i} u, T_{j}^{i} u_{n}\right)+d\left(T_{j}^{i} u_{n}, T_{j}^{i-1} u_{n}\right)+\cdots+d\left(T_{j} u_{n}, u_{n}\right) \\
& \leq d\left(u, u_{n}\right)+k_{j n} \xi_{j}\left(d\left(u, u_{n}\right)\right)+\varphi_{j n}+\sum_{r=0}^{i-1} d\left(T_{j}^{r} u_{n}, T_{j}^{r+1} u_{n}\right) \\
& \leq\left(1+k_{j n} M_{j}^{*}\right) d\left(u, u_{n}\right)+k_{j n} \xi_{j}\left(M_{j}\right)+\varphi_{j n}+\sum_{r=0}^{i-1} d\left(T_{j}^{r} u_{n}, T_{j}^{r+1} u_{n}\right) .
\end{aligned}
$$

Taking lim sup on both sides of the above estimate and utilizing (3.9) and the fact that each $T_{j}$ is uniformly continuous, we have

$$
r\left(z_{i},\left\{u_{n}\right\}\right)=\limsup _{n \rightarrow \infty} d\left(z_{i}, u_{n}\right) \leq \limsup _{n \rightarrow \infty} d\left(u, u_{n}\right)=r\left(u,\left\{u_{n}\right\}\right) .
$$

This implies that $\left|r\left(z_{i},\left\{u_{n}\right\}\right)-r\left(u,\left\{u_{n}\right\}\right)\right| \rightarrow 0$ as $i \rightarrow \infty$. It follows from Lemma 2.5 that $\lim _{i \rightarrow \infty} T_{j}^{i} u=u$. Again, utilizing the uniform continuity of $T_{j}$, we have $T_{j}(u)=$ $T_{j}\left(\lim _{i \rightarrow \infty} T_{j}^{i} u\right)=\lim _{i \rightarrow \infty} T_{j}^{i+1} u=u$. From the arbitrariness of $j$, we conclude that $u$ is the common fixed point of $\left\{T_{j}\right\}_{j=1}^{m}$. It remains to show that $x=u$. In fact, uniqueness of the asymptotic center implies that

$$
\begin{array}{r}
\limsup _{n \rightarrow \infty} d\left(u_{n}, u\right)<\limsup _{n \rightarrow \infty} d\left(u_{n}, x\right) \\
\leq \limsup _{n \rightarrow \infty} d\left(x_{n}, x\right) \\
<\limsup _{n \rightarrow \infty} d\left(x_{n}, u\right) \\
=\limsup _{n \rightarrow \infty} d\left(u_{n}, u\right) .
\end{array}
$$

This is a contradiction. Hence $x=u$. This implies that $u$ is the unique asymptotic center of $\left\{x_{n}\right\}$ for every subsequence $\left\{u_{n}\right\}$ of $\left\{x_{n}\right\}$. This completes the proof.

The strong convergence of iteration process (1.1) can easily be established under the compactness condition of $K$ or $T(K)$. As a consequence, we can get a generalized version 
of Theorem 12 in [1] and Theorem 3.3 in [17] to the general setup of uniformly convex hyperbolic spaces, respectively. Next, we give a necessary and sufficient condition for the strong convergence of iteration process (1.1).

Theorem 3.5 Let $K$ be a nonempty, closed, and convex subset of a uniformly convex hyperbolic space $X$ with monotone modulus of uniform convexity $\eta$ and let $\left\{T_{i}\right\}_{i=1}^{m}: K \rightarrow K$ be a finite family of uniformly continuous total asymptotically nonexpansive mappings with sequences $\left\{k_{i n}\right\}$ and $\left\{\varphi_{i n}\right\}, n \geq 1, i=1,2, \ldots, m$. Suppose that $F:=\bigcap_{i=1}^{m} F\left(T_{i}\right) \neq \phi$ and the following conditions are satisfied:

(C1) $\sum_{n=1}^{\infty} k_{\text {in }}<\infty$ and $\sum_{n=1}^{\infty} \varphi_{\text {in }}<\infty$;

(C2) there exist constants $M_{i}, M_{i}^{*}>0$ such that $\xi_{i}\left(\lambda_{i}\right) \leq M_{i}^{*} \lambda_{i}$ for all $\lambda_{i} \geq M_{i}$,

then the sequence $\left\{x_{n}\right\}$ defined in (1.1) converges strongly to a point in $F$ if and only if $\liminf _{n \rightarrow \infty} d\left(x_{n}, F\right)=0$.

Proof The necessity of the conditions is obvious. Thus, we only prove the sufficiency. It follows from Lemma 2.6 that $\left\{d\left(x_{n}, p\right)\right\}_{n=1}^{\infty}$ converges. Moreover, $\liminf _{n \rightarrow \infty} d\left(x_{n}, F\right)=0$ implies that $\lim _{n \rightarrow \infty} d\left(x_{n}, F\right)=0$. This completes the proof.

It is remarked that there are certain situations when the domain $D(T)$ of a nonlinear mapping $T$ is a proper subset of the underlying space $X$. In such situations, the iterative schema for the approximation of fixed points of $T$ may fail to be well defined. It is therefore natural to study the non-self behavior of the nonlinear mappings.

We recall that a non-self-mapping $T: K \rightarrow X$ is called a total asymptotically nonexpansive mapping if there exist nonnegative real sequences $\left\{k_{n}\right\}$ and $\left\{\varphi_{n}\right\}$ with $k_{n} \rightarrow 0$ and $\varphi_{n} \rightarrow 0$ as $n \rightarrow \infty$ and a strictly increasing continuous function $\xi: \mathbb{R}^{+} \rightarrow \mathbb{R}^{+}$with $\xi(0)=0$, such that

$$
d\left(T(P T)^{n-1} x, T(P T)^{n-1} y\right) \leq d(x, y)+k_{n} \xi(d(x, y))+\varphi_{n} \quad \text { for all } x, y \in K, n \geq 1,
$$

where $P: X \rightarrow K$ is a nonexpansive retract.

Hence, one can establish the strong and $\triangle$-convergence results - as in Theorems 3.4 and 3.5 with a slight modification - for the following iteration schema involving a finite family of totally asymptotically nonexpansive non-self-mappings:

$$
\begin{aligned}
& x_{1} \in K, \\
& x_{n+1}=P\left(W\left(x_{n}, T_{1}\left(P T_{1}\right)^{n-1} x_{n}, \alpha_{n}\right)\right) \quad \text { if } m=1, n \geq 1, \\
& x_{1} \in K, \\
& x_{n+1}=P\left(W\left(x_{n}, T_{1}\left(P T_{1}\right)^{n-1} y_{1 n}, \alpha_{n}\right)\right), \\
& y_{1 n}=P\left(W\left(x_{n}, T_{2}\left(P T_{2}\right)^{n-1} y_{2 n}, \alpha_{n}\right)\right), \\
& y_{2 n}=P\left(W\left(x_{n}, T_{3}\left(P T_{3}\right)^{n-1} y_{3 n}, \alpha_{n}\right)\right), \\
& \ldots, \\
& y_{(m-2) n}=P\left(W\left(x_{n}, T_{m-1}\left(P T_{m-1}\right)^{n-1} y_{(m-1) n}, \alpha_{n}\right)\right), \\
& y_{(m-1) n}=P\left(W\left(x_{n}, T_{m}\left(P T_{m}\right)^{n-1} x_{n}, \alpha_{n}\right)\right) \quad \text { if } m \geq 2, n \geq 1 .
\end{aligned}
$$




\section{Remark 3.6}

(i) It is worth mentioning that Theorems 3.4 and 3.5 can easily be extended to the class of mappings with bounded error terms as well as to approximate common fixed points of total asymptotically nonexpansive semigroup;

(ii) Lemma 2.6 improves and generalizes Theorem 7 in [1] and Lemma 3.1(i) in [17] to the general setup of uniformly convex hyperbolic spaces, respectively;

(iii) Lemma 2.7 improves and generalizes Theorem 11 in [1] and Lemma 3.1(iii) in [17] to the setting as mentioned in (ii);

(iv) Theorem 3.4 improves Theorem 3.5 in [11] and Theorem 3.1 in [14] for a finite family of total asymptotically nonexpansive mappings to the setup of spaces as mentioned in (ii);

(v) Theorem 3.4 sets an analog of Theorem 3.2 in [17] in the setting as mentioned in (ii);

(vi) Theorem 3.5 generalizes Theorem 8 in [1] and Theorem 2.2 in [17] to the setting as defined in (ii).

\section{Competing interests}

The authors declare that they have no competing interests.

\section{Authors' contributions}

All authors contributed equally and significantly in writing this paper. All authors read and approved the final manuscript.

\section{Author details}

${ }^{1}$ Department of Mathematics, COMSATS Institute of Information Technology, Lahore, 54000, Pakistan. ${ }^{2}$ Department of Mathematics and Statistics, King Fahd University of Petroleum and Minerals, Dhahran, 3126, Saudi Arabia. ${ }^{3}$ Department of Mathematics, The Islamia University of Bahawalpur, Bahawalpur, 63100, Pakistan.

\section{Acknowledgements}

The authors are very grateful to the editor and anonymous referees for their helpful comments. The author H Fukhar-ud-din is grateful to King Fahd University of Petroleum and Minerals for supporting this research.

Received: 24 February 2015 Accepted: 6 December 2015 Published online: 06 January 2016

\section{References}

1. Chidume, CE, Ofoedu, EU: Approximation of common fixed points for finite families of total asymptotically nonexpansive mappings. J. Math. Anal. Appl. 333, 128-141 (2007)

2. Kohlenbach, U: Some logical metatheorems with applications in functional analysis. Trans. Am. Math. Soc. 357, 89-128 (2005)

3. Goebel, K, Kirk, WA: Iteration processes for nonexpansive mappings. In: Singh, SP, Thomeier, S, Watson, B (eds.) Topological Methods in Nonlinear Functional Analysis. Contemporary Mathematics, vol. 21, pp. 115-123. Am. Math. Soc., Providence (1983)

4. Goebel, K, Reich, S: Uniform Convexity, Hyperbolic Geometry, and Nonexpansive Mappings. Dekker, New York (1984)

5. Reich, S, Zasalvski, AJ: Genericity in Nonlinear Analysis. Springer, New York (2014)

6. Reich, S, Shafrir, I: Nonexpansive iterations in hyperbolic spaces. Nonlinear Anal. 15, 537-558 (1990)

7. Takahashi, W: A convexity in metric spaces and nonexpansive mappings. Kodai Math. Semin. Rep. 22, 142-149 (1970)

8. Matouskova, E, Reich, S: Reflexivity and approximate fixed points. Stud. Math. 159, 403-415 (2004)

9. Leuştean, L: A quadratic rate of asymptotic regularity for CAT(0)-spaces. J. Math. Anal. Appl. 325, 386-399 (2007)

10. Alber, $\mathrm{Yl}$, Chidume, CE, Zegeye, $\mathrm{H}$ : Approximating fixed points of total asymptotically nonexpansive mappings. Fixed Point Theory Appl. 2006, Article ID 10673 (2006)

11. Chang, SS, Wang, L, Lee, HWJ, Chan, CK, Yang, L: Demiclosed principle and $\triangle$-convergence theorems for total asymptotically nonexpansive mappings in CAT(0) spaces. Appl. Math. Comput. 219, 2611-2617 (2012)

12. Fukhar-ud-din, H, Khan, AR: Approximating common fixed points of asymptotically nonexpansive maps in uniformly convex Banach spaces. Comput. Math. Appl. 53, 1349-1360 (2007)

13. Fukhar-ud-din, H, Khan, AR, Khan, MAA: A new implicit algorithm of asymptotically quasi-nonexpansive mappings in uniformly convex Banach spaces. IAENG Int. J. Appl. Math. 42(3), 1-5 (2012)

14. Khan, MAA: Convergence analysis of a multi-step iteration for a finite family of asymptotically quasi-nonexpansive mappings. J. Inequal. Appl. 2013, 423 (2013). doi:10.1186/1029-242X-2013-423

15. Khan, MAA, Fukhar-ud-din, $\mathrm{H}$ : Convergence analysis of a general iteration schema of nonlinear mappings in hyperbolic spaces. Fixed Point Theory Appl. 2013, 238 (2013). doi:10.1186/1687-1812-2013-238

16. Yildirim, I, Khan, $\mathrm{SH}$ : Convergence theorems for common fixed points of asymptotically quasi-nonexpansive mappings in convex metric spaces. Appl. Math. Comput. 218, 4860-4866 (2012)

17. Khan, AR, Domlo, AA, Fukhar-ud-din, H: Common fixed points Noor iteration for a finite family of asymptotically quasi-nonexpansive mappings in Banach spaces. J. Math. Anal. Appl. 341, 1-11 (2008) 
18. Kuhfittig, PKF: Common fixed points of nonexpansive mappings by iteration. Pac. J. Math. 97, 137-139 (1981)

19. Khan, AR, Ahmad, MA: Convergence of a general iterative scheme for a finite family of asymptotically quasi-nonexpansive mappings in convex metric spaces and applications. Comput. Math. Appl. 59, 2990-2995 (2010)

20. Khan, AR, Khamsi, MA, Fukhar-ud-din, H: Strong convergence of a general iteration scheme in CAT(0) spaces. Nonlinear Anal. 74, 783-791 (2011)

21. Edelstein, M: The construction of an asymptotic center with a fixed point property. Bull. Am. Math. Soc. 78, 206-208 (1972)

22. Lim, TC: Remarks on some fixed point theorems. Proc. Am. Math. Soc. 60, 179-182 (1976)

23. Kirk, W, Panyanak, B: A concept of convergence in geodesic spaces. Nonlinear Anal. 68, 3689-3696 (2008)

24. Leuştean, L: Nonexpansive iterations in uniformly convex W-hyperbolic spaces. In: Leizarowitz, A, Mordukhovich, BS, Shafrir, I, Zaslavski, A (eds.) Nonlinear Analysis and Optimization I: Nonlinear Analysis. Contemporary Mathematics, vol. 513, pp. 193-209. Am. Math. Soc., Providence (2010)

25. Kohlenbach, U, Leuştean, L: Asymptotically nonexpansive mappings in uniformly convex hyperbolic spaces. J. Eur. Math. Soc. 12, 71-92 (2010)

26. Chang, SS, Cho, YJ, Zhou, H: Demiclosed principal and weak convergence problems for asymptotically nonexpansive mappings. J. Korean Math. Soc. 38(6), 1245-1260 (2001)

27. Khan, AR, Fukhar-ud-din, H, Khan, MAA: An implicit algorithm for two finite families of nonexpansive maps in hyperbolic spaces. Fixed Point Theory Appl. 2012, 54 (2012). doi:10.1186/1687-1812-2012-54

28. Suantai, S, Phuengrattana, W: Fixed point theorems for a semigroup of total asymptotically nonexpansive mappings in uniformly convex Banach spaces. Opusc. Math. 34(1), 183-197 (2014)

\section{Submit your manuscript to a SpringerOpen ${ }^{\circ}$ journal and benefit from:}

- Convenient online submission

Rigorous peer review

- Immediate publication on acceptance

- Open access: articles freely available online

- High visibility within the field

- Retaining the copyright to your article 